\title{
Circularly polarized rectangular dielectric resonator antenna excited by an off-set conformal metal strip
}

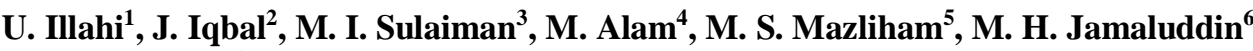 \\ ${ }^{1,3}$ Universiti Kuala Lumpur British Malaysian Institute, Malaysia \\ ${ }^{1,2}$ Gomal University, Pakistan \\ ${ }^{4}$ ILMA University, Pakistan \\ ${ }^{4}$ Universiti Kuala Lumpur Malaysian Institute of Information Technology, Malaysia \\ ${ }^{5}$ Universiti Kuala Lumpur, Malaysia \\ ${ }^{6}$ Universiti Teknologi Malaysia, Faculty of Electrical Engineering, Malaysia
}

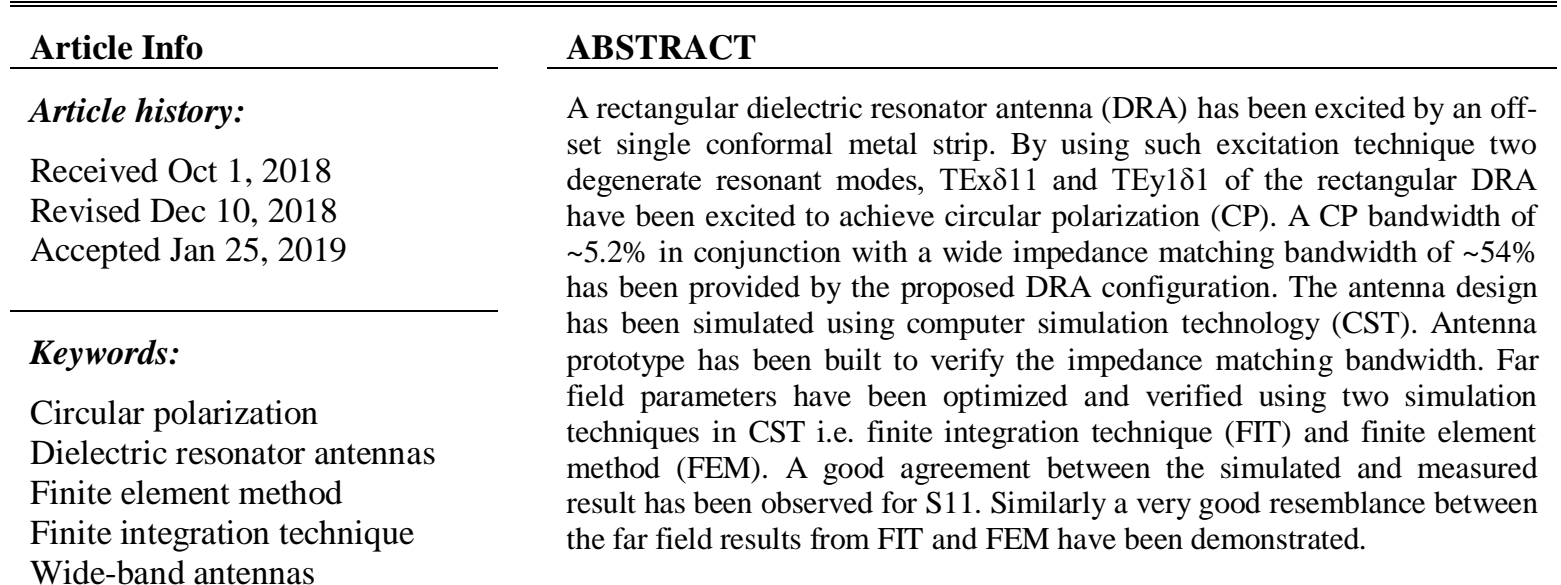

\section{Corresponding Author:}

Mohamad Ismail Sulaiman,

Communication Technology Section,

Universiti Kuala Lumpur British Malaysian Institute,

Jalan Sungai Pusu, 53100 Gombak, Selangor, Malaysia.

Email: mismail@unikl.edu.my

\section{INTRODUCTION}

In recent years, dielectric resonator antennas (DRAs) have been acquiring the focus of researchers due their attractive features such as flexible design, no metallic losses, wider bandwidth and may more [1-27]. The linearly polarized systems are more susceptible to losses, whereas the circularly polarized systems are much more reliable. The circular polarization of DRA can be achieved by using dual feeding technique but at the cost of larger size and complexity of feeding network [12-14]. The single feeding mechanism is much more popular due to simple network and compact size. Many circularly polarized DRAs excited by single feeding technique have been reported in literature. A 3dB axial ration (AR) bandwidth of $2.7 \%$ of a rectangular DRA has been achieved by parasitic patch [15]. A CP bandwidth of $6.3 \%$ achieved by truncating the opposite corners on the rectangular DRA has been reported in [16]. A cross slot fed rectangular DRA with 3.5\% CP bandwidth has been demonstrated in [17]. A circularly polarized two-layer rectangular DRA with $9.5 \% \mathrm{CP}$ bandwidth, excited by a cross slot microstrip line feed has been reported in [18]. A 7.2\% CP bandwidth of a rectangular DRA has been achieved by T-shaped feed [19]. As demonstrated in [20], a spiral strip has been used to achieve $7 \% \mathrm{CP}$ bandwidth of a rectangular DRA. An $11 \%$ axial ratio bandwidth of a singly fed rectangular DRA has been achieved by parasitic patch as reported in [21]. An off- 
centered microstrip line has been used to excite a cylindrical DRA to achieve $3 \mathrm{~dB}$ axial ratio bandwidth of $3.47 \%$ [22]. A semi-eccentric annular DRA excited by a coaxial probe has provided CP bandwidth of 5.17\% as reported in [23]. As reported in [24] an 18\% CP bandwidth of a loop antenna printed on a layered dielectric sphere has been achieved by probe feeding. In all discussed articles the antennas provide good impedance matching bandwidth over same frequency range.

In this article the $\mathrm{CP}$ of rectangular DRA has been achieved by an off-set single conformal metal strip. Using this simple and economical excitation technique, a $\mathrm{CP}$ bandwidth of $5.2 \%$ has been obtained. A wide impedance matching bandwidth of $54 \%$ has been offered by the antenna over same frequency range

\section{RESEARCH METHOD}

A rectangular DRA fed by an off-set single conformal metal strip has been illustrated in Figure 1. The antenna configuration has been modeled using a time-domain integral equation (TDIE) based on FIT [25].

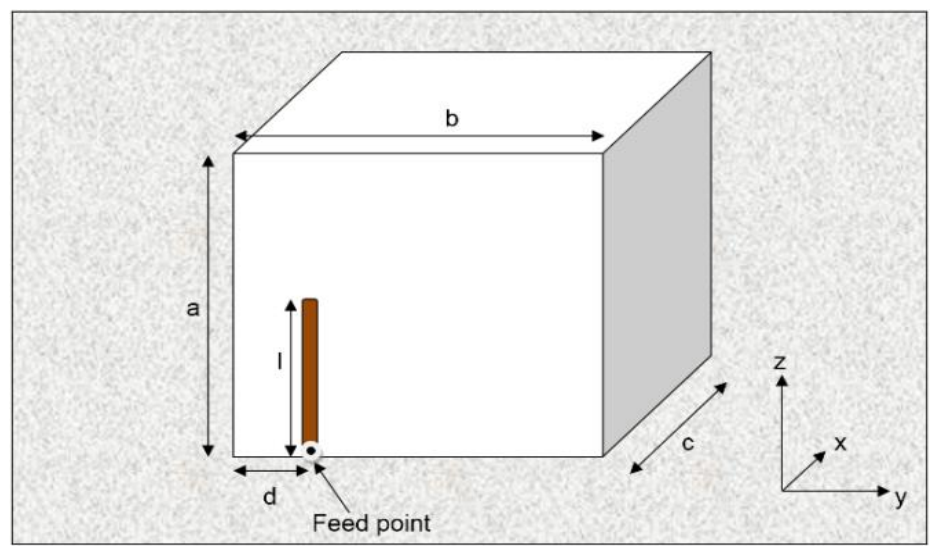

Figure 1. Rectangular DRA fed by an off-set conformal metal strip

The design has been built using the hexahedral meshing in which setting the cells per wavelength $=$ 40 , similarly the cells per max model box edge $=20$. The fraction of maximum cell near to model $=20$ and the number of Cells $=555,519$. In boundary conditions $\mathrm{Zmin}$ has been set at Electric $(\mathrm{Et}=0)$ to simulate the effect of infinite ground plane. The DRA block has been excited by a single conformal metallic strip and single port has been used to energize the model. The iterative design procedure has been adopted to optimize the feed position to excite two degenerate modes to generate circularly polarized wave [16].

The length and width of the strip has been optimized by running many simulations with different parameter sweeps. The results of optimized design from FIT has been validated by fabrication for near field and by FEM for far field results. Prototype of the rectangular DRA as shown in Figure 2.

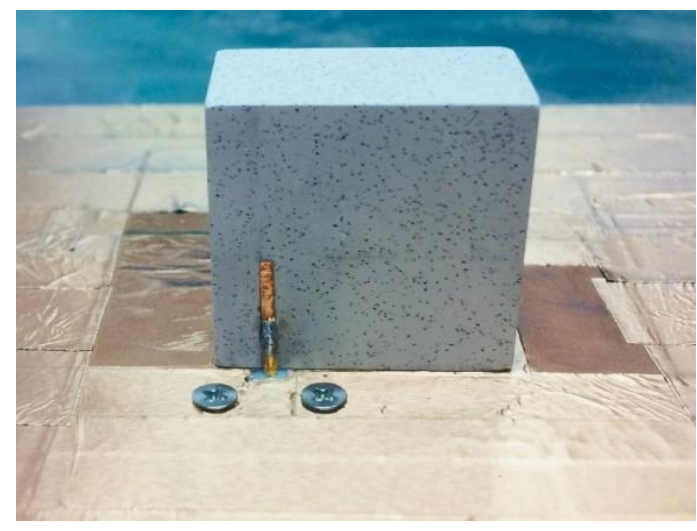

Figure 2. Prototype of the Rectangular DRA 


\section{RESULTS AND DISCUSSIONS}

The antenna prototype illustrated in Figure 2 has been built using the ECCOSTOCK HiK with permittivity $\varepsilon r=10$. The dimensions of dielectric block; $a=26.1 \mathrm{~mm}, \mathrm{~b}=25.4 \mathrm{~mm}$ and $\mathrm{c}=14.3 \mathrm{~mm}$ have been chosen based from [15]. The conformal metal strip has been cut from adhesive-backed copper tape to stick easily on the DRA surface.

In Figure. 3 the comparison between simulated and measured return losses of the rectangular DRA excited by an off-set conformal metal strip have been presented. As shown the impedance matching i.e. |S11| $\leq 10 \mathrm{~dB}$ bandwidth has been achieved over a wide bandwidth of $\sim 54 \%$. The feed position has been shifted to excite the degenerate mode pair for $\mathrm{CP}$ wave generation. The optimized strip position and parameters are $\mathrm{d}=$ $4 \mathrm{~mm}$ and $1=11 \mathrm{~mm}$. The width of the metal strip is $1 \mathrm{~mm}$. An aluminum ground plane of $300 \times 300 \mathrm{~mm} 2$ has been employed. The two degenerate modes i.e. TEx $\delta 11$ at $2.784 \mathrm{GHz}$ and TEy1 $\delta 1$ at $3.697 \mathrm{GHz}$ have been excited as shown by the Figure 4.

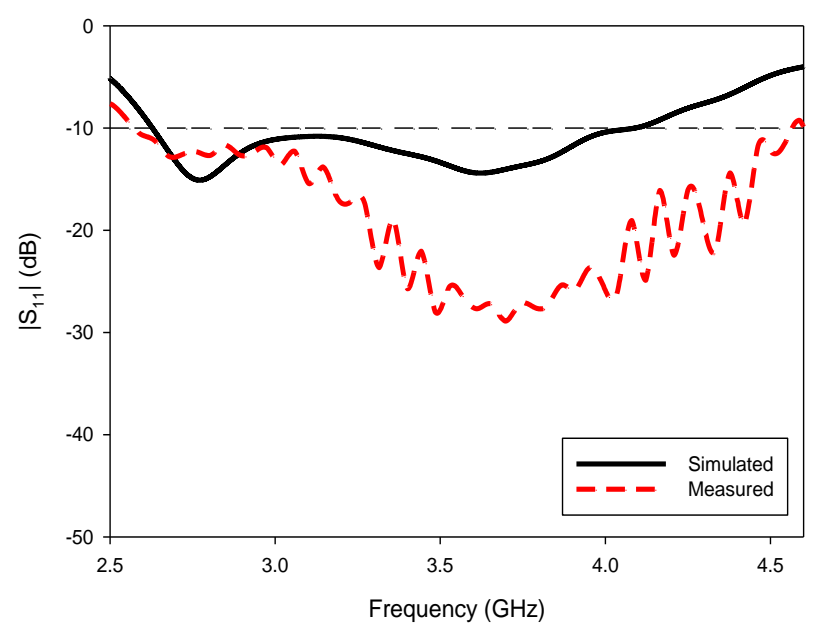

Figure 3. Return losses of the rectangular DRA fed by an off-set conformal metal strip
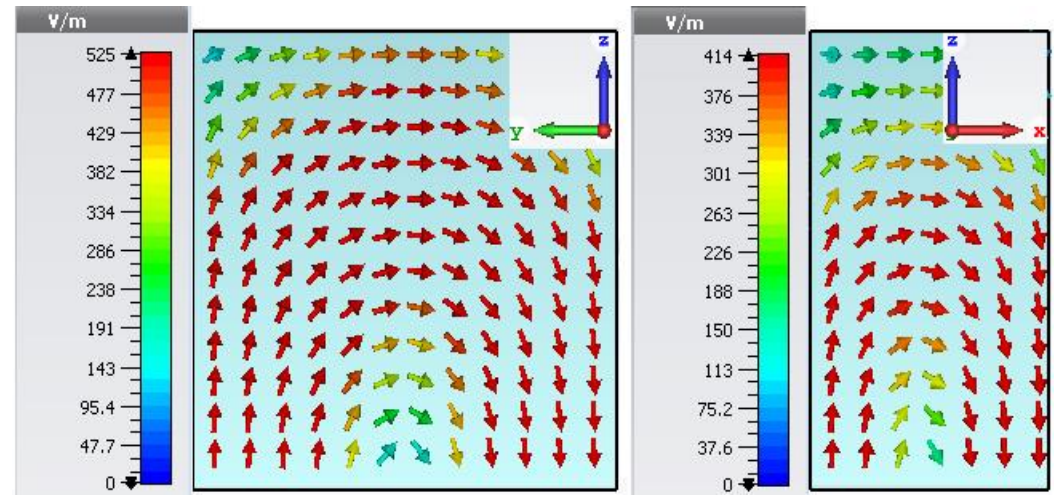

Figure 4. E-field distribution for TEx $\delta 11$ and TEy $1 \delta 1$

For comparison, the resonant modes frequencies of the rectangular DRA have also been calculated using dielectric waveguide model (DWM) proposed in [26]. The frequency for TEx $\delta 11$ mode can be calculated using:

$$
\begin{aligned}
& k_{y}=\frac{\pi}{b} \\
& k_{z}=\frac{\pi}{a}
\end{aligned}
$$


$k_{x} \tan \left(k_{x} c / 2\right)=\sqrt{\left(\varepsilon_{r}-1\right) k_{0}^{2}-k_{x}^{2}}$

Similarly frequency for TEy1 $\delta 1$ mode can be calculated using:

$$
\begin{aligned}
& k_{x}=\frac{\pi}{c} \\
& k_{z}=\frac{\pi}{a} \\
& k_{y} \tan \left(k_{y} b / 2\right)=\sqrt{\left(\varepsilon_{r}-1\right) k_{0}^{2}-k_{y}^{2}}
\end{aligned}
$$

Where $\mathrm{kx}$, ky and $\mathrm{kz}$ denote the wavenumbers in the $\mathrm{x}, \mathrm{y}$ and $\mathrm{z}$ directions inside the DRA and $\mathrm{k} 0$ represents the free space wavenumber. Additionally, the wavenumbers must satisfy the following:

$$
\begin{aligned}
& k_{x}^{2}+k_{y}^{2}+k_{z}^{2}=\varepsilon_{r} k_{0}^{2} \\
& k_{0}=\frac{2 \pi}{\lambda_{0}}=\frac{2 \pi f_{0}}{c}
\end{aligned}
$$

Where $\lambda 0$ is the free-space wavelength, and $\mathrm{c}$ is the speed of light in vacuum. Substitution of (8) in (7) yields the resonance frequency as:

$$
f_{0}=\frac{c}{2 \pi \varepsilon_{r}} \sqrt{k_{x}^{2}+k_{y}^{2}+k_{z}^{2}}
$$

The calculated frequency by DWM for TEx $\delta 11$ mode is found to be $2.712 \mathrm{GHz}$ compared to 2.784 $\mathrm{GHz}$ obtained by measurement. Similarly the calculated frequency by DWM for TEy1 $\delta 1$ mode is $3.708 \mathrm{GHz}$ that is close enough to $3.697 \mathrm{GHz}$ obtained experimentally. Hence a good agreement has been observed between calculated and measured values.

Figure 5 represents the axial ratio of the rectangular DRA in bore-sight direction. As demonstrated the AR bandwidth of $\sim 5.2 \%$ has been provided by the antenna. The minimum point of axial ratio i.e. $2.33 \mathrm{~dB}$ is at $3.09 \mathrm{GHz}$ in FIT and at $3.08 \mathrm{GHz}$ in FEM. The small marginal shift can be attributed to different computational environment of two techniques used. As presented in Figure 6, the minimum AR point lies in between two degenerate modes as explained in [16]. Moreover a wide impedance matching bandwidth has been achieved over same frequency range.

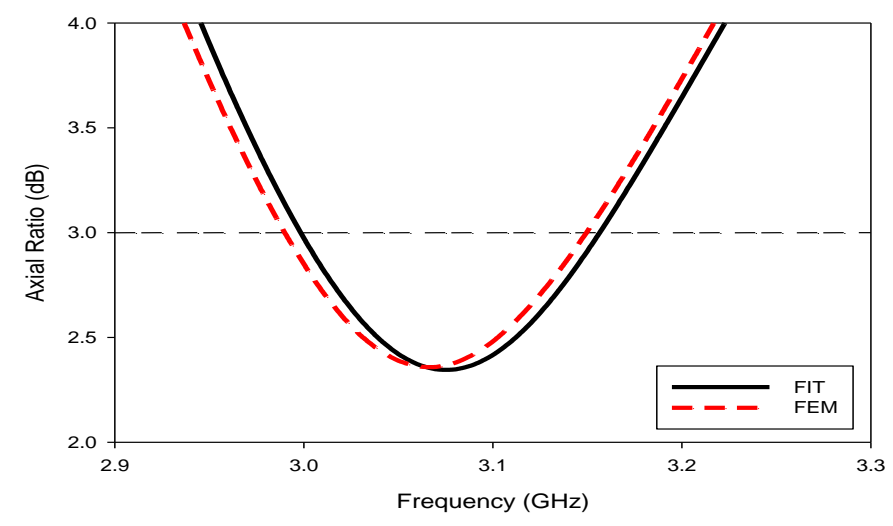

Figure 5. Axial ratio of the rectangular DRA fed by an off-set conformal metal strip

Circularly polarized rectangular dielectric resonator antenna excited by an off-set conformal... (U. Illahi) 


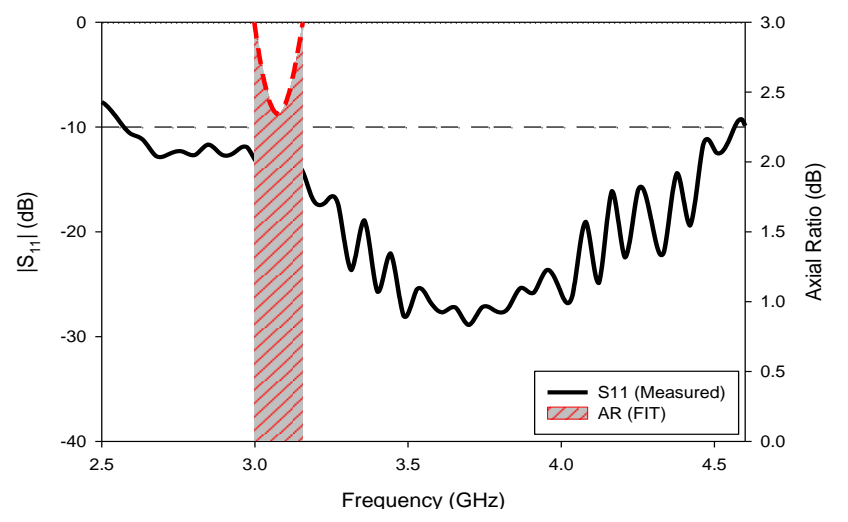

Figure 6. The region of bandwidths overlap of the rectangular DRA fed by an off-set conformal metal strip

In Figure 7, the radiation patterns of the antenna has been demonstrated. At minimum point of AR frequency i.e. $3.08 \mathrm{GHz}$ the left hand field component is greater than right hand field component, hence proving that antenna offers a left-hand circularly polarized wave. The direction of polarization can be reversed by making the strip off-set to right side from center rather than left.
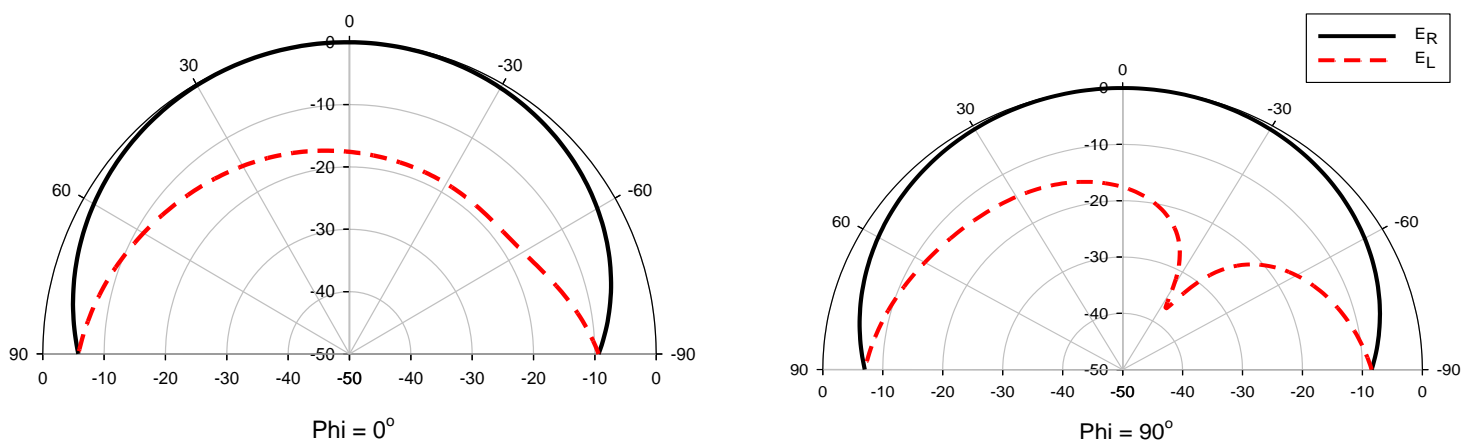

Figure 7. Radiation patterns of the rectangular DRA fed by an off-set conformal metal strip

The beamwidth offered by the antenna has been presented in Figure 8 . The antenna offers a circular polarization with useful beamwidth of $81 \mathrm{o}$ in the $\phi=0 \mathrm{o}$ plane and $70 \mathrm{o}$ in the $\phi=90 \mathrm{o}$ plane. The beamwidths provided by the antenna are comparable to those reported in [27].

The gain of the rectangular DRA has been demonstrated in Figure 9. The antenna provide a useful gain of $\sim 5.3 \mathrm{dBi}$ throughout the whole CP bandwidth. The gain of the antenna has been demonstrated in both FIT and FEM. A good agreement between the results from FIT and FEM has been observed.
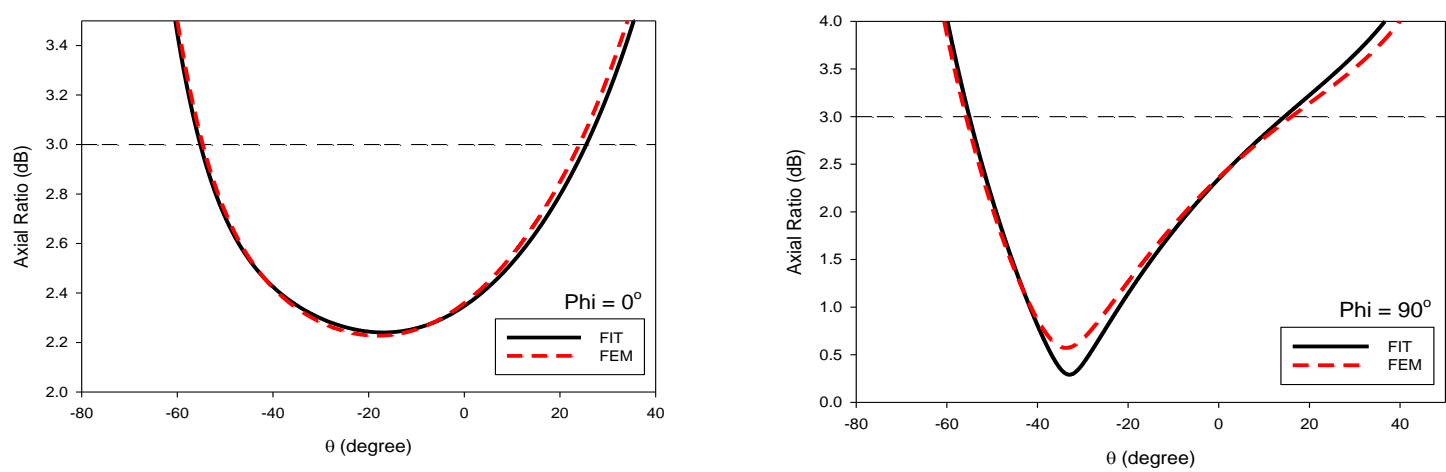

Figure 8. AR beamwidth of the rectangular DRA fed by an off-set conformal metal strip 


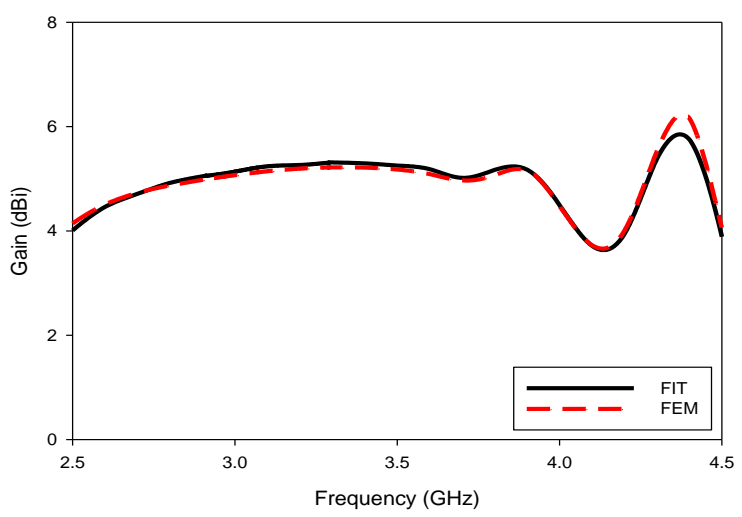

Figure 9. Gain of the rectangular DRA fed by an off-set conformal metal strip

\section{CONCLUSION}

A rectangular DRA has been excited by an off-set single conformal metal strip. A circular polarization over bandwidth of $\sim 5.2 \%$ has been achieved along with a wide impedance matching bandwidth of $\sim 54 \%$ over same frequency range. The two degenerate mode pair i.e. TEx $\delta 11$ at $2.784 \mathrm{GHz}$ and TEyl $\delta 1$ at 3.697 GHz has been excited by an off-set metal strip to achieve CP which is a good contribution in designing circularly polarized rectangular DRAs as compared to those reported in early research studies. The antenna offers a CP beamwidth of 810 in the $\phi=0$ o plane and 70o in the $\phi=90$ o plane. A useful gain of $\sim 5.3 \mathrm{dBi}$ has been provided by the antenna along the whole CP bandwidth. A good resemblance between the simulated and measured S11 has been observed. A similar trend in far field results from FIT and FEM have also been observed.

\section{ACKNOWLEDGEMENTS}

The authors would like to acknowledge the Universiti Kuala Lumpur (UniKL) for providing short term research grant (Str 15073) and research facilities to carry out this research work.

\section{REFERENCES}

[1] N. H. Shahadan, M. H. Jamaluddin, M. H. Dahri, M. R. Kamarudin and K. H. Yusof, "High Gain Switchable Dielectric Resonator Antenna Array for 5G Applications," 2018 International Symposium on Antennas and Propagation (ISAP), Busan, Korea (South), 2018, pp. 1-2.

[2] M. Abedian, S. K. A. Rahim, C. Fumeaux, S. Danesh, Y. C. Lo and M. H. Jamaluddin, "Compact ultrawideband MIMO dielectric resonator antennas with WLAN band rejection," in IET Microwaves, Antennas \& Propagation, vol. 11, no. 11, 2017, pp. 1524-1529.

[3] K. Lu, K. W. Leung and Y. M. Pan, "Theory and Experiment of the Hollow Rectangular Dielectric Resonator Antenna," in IEEE Antennas and Wireless Propagation Letters, vol. 10, 2011, pp. 631-634.

[4] X. Ye and M. He, "A compact circularly polarized cavity-backed antenna with I-type crossed slots," 2011 IEEE International Conference on Microwave Technology \& Computational Electromagnetics, Beijing, 2011, pp. 31-34.

[5] R. Han, S. Zhong and J. Liu, "Design of circularly-polarized dielectric resonator antenna with wideband feed network," Proceedings of 2014 3rd Asia-Pacific Conference on Antennas and Propagation, Harbin, 2014, pp. $48-50$.

[6] W. M. Abdel-Wahab, A. Hussam, S. Safavi-Naeini and Y. Wang, "Circularly polarized SIW-integrated DRA for low cost millimeter wave systems," Global Symposium on Millimeter-Waves (GSMM), Montreal, QC, 2015, pp. 1-3.

[7] R. Kumar and R. K. Chaudhary, "A Wideband Circularly Polarized Cubic Dielectric Resonator Antenna Excited With Modified Microstrip Feed," in IEEE Antennas and Wireless Propagation Letters, vol. 15, 2016, pp. 1285-1288.

[8] L. Lu, Y. Jiao, W. Liang and H. Zhang, "A Novel Low-Profile Dual Circularly Polarized Dielectric Resonator Antenna," in IEEE Transactions on Antennas and Propagation, vol. 64, no. 9, Sept. 2016, pp. 4078-4083.

[9] A. Sharma and R. K. Gangwar, "Circularly polarised hybrid Z-shaped cylindrical dielectric resonator antenna for multiband applications," in IET Microwaves, Antennas \& Propagation, vol. 10, no. 12, Sep. 2016, pp. 12591267. 
[10] D. Subramaniam, M. Jusoh, T. Sabapathy, M.N. Osman, M.R. Kamarudin, M.T. Ali, M.N.M. Yasin, A. Ali, H.A. Majid, and R. Rahim, "A Stacked planar antenna with switchable small grid pixel structure for directive high beam steering broadside radiation,” International Journal of Engineering and Technology (UAE), 7(2.5 Special Issue 5), 2018, pp.122-127.

[11] M. N. M. Yasin and S. K. Khamas, "Measurements and Analysis of a Probe-Fed Circularly Polarized Loop Antenna Printed on a Layered Dielectric Sphere," in IEEE Transactions on Antennas and Propagation, vol. 60, no. 4, , April 2012, pp. 2096-2100.

[12] E. H. Lim, K.W. Leung and X.S. Fang, "The compact circularly-polarized hollow rectangular dielectric resonator antenna with an underlaid quadrature coupler," IEEE Trans. Antennas Propag., vol. 59, no. 1, Jan. 2011, pp. 288-293.

[13] K. W. Leung, W. C. Wong, K. M. Luk, and E. K. N. Yung, "Circularly polarized dielectric resonator antenna excited by dual conformal strips," Electron. Lett., vol. 36, Mar. 2000, pp. 484-486.

[14] W. C. Wong and K. W. Leung, "Circularly polarized dielectric resonator antenna excited by dual conformal strip of unequal lengths," Microw. Opt. Technol. Lett., vol. 29, Jun. 2001, pp. 348-350.

[15] B. Li and K. W. Leung, "Strip-fed rectangular dielectric resonator antenna with/without a parasitic patch," IEEE Trans. Antennas Propag., vol. 53, no. 7, Jul. 2005, pp. 2200-2207.

[16] X. Fang, K. W. Leung and E. H. Lim, "Singly-fed dual-band circularly polarized dielectric resonator antenna," IEEE Antennas and Wireless Propagation Letters, vol. 13, 2014, pp.995-998.

[17] S. Dhar, S. Sankaralingam, B. Gupta, D. R. Poddar and R. Ghatak, "A reconfigurable dielectric resonator antenna for polarization diversity applications," Microwave Symposium (MMS), 14th Mediterranean, IEEE, December 2014, pp. 1-4.

[18] A. A. Abdulmajid, Y. Khalil and S. Khamas, "Higher-Order-Mode Circularly Polarized Two-Layer Rectangular Dielectric Resonator Antenna," IEEE Antennas and Wireless Propagation Letters, 17(6), June 2018, pp.1114-1117.

[19] U. Illahi, J. Iqbal, M. I. Sulaiman, M. Alam and M. S. Mazliham, "A Singly fed Circularly Polarized Rectangular Dielectric Resonator Antenna excited by T-Shaped Conformal Metal Strip,” Journal of Engineering Technology, vol. 5, 2017, pp. 1-4.

[20] M. I. Sulaiman and S.K. Khamas, "A singly fed rectangular dielectric resonator antenna with a wideband circular polarization," IEEE Antennas and Wireless Propagation Letters, vol. 9, 2010, pp.615-618.

[21] J. Iqbal, U. Illahi, M. I. Sulaiman, M. Alam and M. S. Mazliham, "Bandwidth Enhancement of Rectangular Dielectric Resonator Antenna with and Without a Parasitic Patch," Journal of Engineering Technology, vol. 5, 2017, pp. 5-8.

[22] C. C. Lin, and J. S. Sun, "Circularly polarized dielectric resonator antenna fed by off-centered microstrip line for 2.4-GHz ISM band applications," IEEE Antennas and Wireless Propagation Letters, 14, Dec. 2015, pp. 947-949.

[23] J. M. Lee, S. J. Kim, G. Kwon, C. M. Song, Y. Yang, K. Y. Lee, and K. C. Hwang. "Circularly polarized semieccentric annular dielectric resonator antenna for X-band applications," IEEE Antennas and Wireless Propagation Letters, 14, 2015, pp. 1810-1813.

[24] M. N. M. Yasin and S. K. Khamas, "Measurements and Analysis of a Probe-Fed Circularly Polarized Loop Antenna Printed on a Layered Dielectric Sphere," IEEE Trans. Antennas Propag., vol. 60, no. 4, April 2012, pp. 2096-2100.

[25] T. Weiland. "Time domain electromagnetic field computation with finite difference methods," Int. J. Numer. Model. El., 9(4), July-August 1996, pp. 295-319.

[26] R. K. Mongia, "Theoretical and experimental resonant frequencies of rectangular dielectric resonators," IEEE Proc.H, vol. 139, no. 1, Feb. 1992, pp. 98-104.

[27] M. T. K. Tam and R. D. Murch, "Circularly polarized circular sector dielectric resonator antenna," IEEE Trans. Antennas Propag., vol. 48, no. 1, Jan. 2000, pp. 126-128.

\section{BIOGRAPHIES OF AUTHORS}

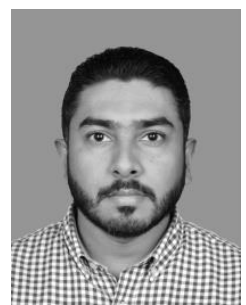

USMAN ILLAHI received the B.Sc. degree in electrical engineering from NWFP University of Engineering and Technology, Peshawar, Pakistan, in 2007, the M.Sc. degree in electronic communication and computer engineering, from The University of Nottingham Malaysia Campus, in 2013, and he is currently doing Ph.D. in electrical and electronic engineering from Universiti Kuala Lumpur, Malaysia, with a focus on antenna microwave communication systems and especially antennas, such as dielectric resonators antennas, circularly polarized antennas, wideband antennas, and wearable antennas. 


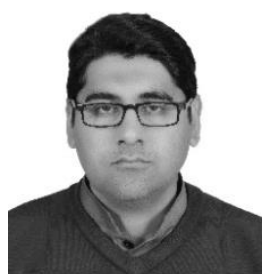

JAVED IQBAL received the B.Sc. degree in telecommunication engineering from NWFP University of Engineering and Technology, Peshawar, Pakistan, in 2007, the M.Sc. degree in electronic communication and computer engineering, from The University of Nottingham Malaysia Campus, in 2013, and he is currently doing Ph.D. in electrical and electronic engineering from Universiti Kuala Lumpur, Malaysia, with a focus on antenna microwave communication systems and especially antennas, such as dielectric resonators antennas, circularly polarized antennas, wideband antennas, and MIMO antennas.

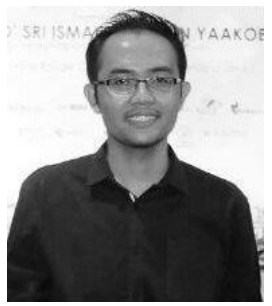

MOHAMAD ISMAIL SULAIMAN received the Ph.D. and M.Eng degree in electronic engineering (communications) from the University of Sheffield, United Kingdom in 2012 and 2007, respectively. Since 2013, he has been a Senior Lecturer at Universiti Kuala Lumpur British Malaysian Institute. His research interests include computational electromagnetics, dielectric resonator antennas, circularly polarized antennas, wideband antennas, mutual coupling, and wearable antenna. He has authored more than 30 research articles published in journals and peer reviewed conferences.

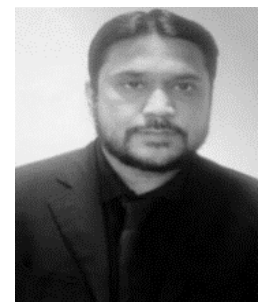

MUHAMMAD MANSOOR ALAM holds Ph.D. in computer Engineering, Ph.D. in electrical and electronic engineering, M.E. systems sngineering and M.Sc. computer science. He is an active researcher in the field of telecommunication and network. He has authored more than 60 research articles published in ISI indexed journals, as book chapters and in peer reviewed conferences. He is also an author of the book "Study guide of Network Security" copyrighted by Open University Malaysia and Open University Hong Kong. He is also an active reviewer of ISI indexed journal "Pertanika journal of science and technology (JST)".

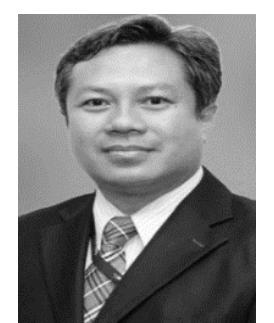

MAZLIHAM MOHD SU'UD Received his PhD from Université de La Rochelle in computer engineering in 2007 and Master's degree in electrical and electronics engineering from University of Montpellier in 1993 and Since 2013 he is working as President/CEO of Universiti Kuala Lumpur Malaysia.

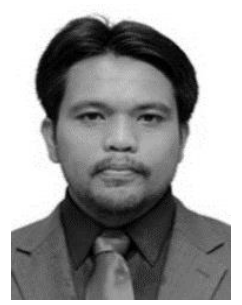

MOHD HAIZAL JAMALUDDIN received the bachelor's and master's degrees in electrical engineering from Universiti Teknologi Malaysia, Malaysia, in 2003 and 2006, respectively, and the Ph.D. degree in signal processing and telecommunications from the Universite de Rennes 1, France, in 2009, with a focus on microwave communication systems and specially antennas, such as dielectric resonator and reflectarray and dielectric dome antennas. He is currently an Associate Professor with the Wireless Communication Centre, School of Electrical Engineering, Universiti Teknologi Malaysia. His research interests include dielectric resonator antennas, printed microstrip antennas, MIMO antennas, and DRA reflectarray antennas. He has published over 100 papers in reputed indexed journals and conference proceedings 